\title{
Teacher's Self-Efficacy on Designing Digital Material in E-Learning: A Case Study in a Vocational School
}

\author{
Untari G. Pertiwi ${ }^{1 *}$, Evi A. Vebriyanti ${ }^{1}$, Lusia M. Nurani ${ }^{1}$, and Dana Waskita ${ }^{1}$ \\ ${ }^{1}$ Literature, Media, and Culture Research Group, Faculty of Arts and Design, Institut Teknologi Bandung \\ *Corresponding author. Email: untari@itb.ac.id
}

\begin{abstract}
In this digital era, transforming the traditional classroom to the online environment becomes urgent, particularly during the COVID 19 pandemic. E-learning becomes an alternative platform for online learning as it provides space for the teacher to open, design, and manage a class. Designing digital material becomes a prerequisite in this circumstance, and it requires teachers' competence in using technology, including digital literacy. This competence will cultivate teachers' self-efficacy, which is an essential factor in the success of E-learning implementation; therefore, this study investigates teachers' self-efficacy on designing digital material uploaded in E-learning. This study explores 20 vocational school teachers' experience in using E-learning by investigating what digital material and E-learning are perceived by the teachers and how they design and implement it in the E-learning. The teachers' experience is captured through questionnaires, interviews and class observation then the data are analysed under Efficacy theory. The result shows that the teachers' self-efficacy, in general, is at a medium level, and their ICT knowledge and competence influence their ability in designing digital material and use it in E-learning. Those with adequate knowledge and competency pose a high self-efficacy, while those with less knowledge and skill, their selfefficacy in designing is considered moderate. Therefore, intensive teacher training in digitalizing material is urgent to boost the teachers' self-efficacy and ICT competence to gain success and benefits from E-learning.
\end{abstract}

Keywords: E-learning, digital material, self-efficacy

\section{INTRODUCTION}

Online learning gains greater attention and the increasing user of Internet and Communication Technology (ICT) in any aspect of daily life activities, including in education fields, due to its benefits to enhance human interaction. ICT makes human interaction possible without time, space, and distance boundaries. This circumstance also applies to classroom interaction that enables educators to conduct teaching and learning activities in an online environment [1]. Previously, online learning evokes to respond to the need for distance learning since online learning offers opportunities to conduct teaching and learning activities in an unlimited distance or remote learning. Therefore, it merely serves as an alternative way of providing education service.

Moreover, online learning in higher education gains a high interest as it is reflected from a number of students enrolling for online courses ten times faster than the actual one [2], and online learning is for distance learning [3]. However, online learning has become mandatory in education institutions starting from primary to tertiary level due to a temporary school close as the impact of social distancing during the
COVID 19 pandemic. UNESCO [4] reports the school closure effects to more than 1.5 billion students in 165 countries. This condition forces a sudden change from traditional learning to online learning. As a result, the Elearning platform becomes an option to conduct online learning in higher education and secondary school.

This shifting is a huge task for all layers in education institutions, including teachers. It emerges many challenges such as limited infrastructure, access, and competency regarding the technology used for teaching and learning [5]. Teachers' competency in operating the technology becomes crucial since the demand includes capability in an online design course that influences online learning success. Specifically, Benson and Barck [6] claim that course developers in Elearning must consider learning theory and learners' characteristics to attain the benefits of E-learning. Moreover, user satisfaction, in this case, a teacher, also contributes to the success. Therefore, it is seen that teachers' motivation is very important in online learning. This motivation can be triggered by the teacher's self-efficacy toward using E-learning, including designing the digital material uploaded on the platform. The teacher's self-efficacy determines the 
teacher's commitment, effort, and innovation during the instruction [7]. Considering the importance of teachers' self-efficacy in online learning using E-learning, this study explores the teacher's self-efficacy in designing digital material in E-learning in vocational schools.

\section{LITERATURE REVIEW}

\subsection{Self-Efficacy}

Teachers' self-efficacy becomes a crucial issue in achieving success in teaching and learning since it influences the teacher readiness in conducting the instruction. According to Bandura [8], self-efficacy emerges from someone's experience in completing a task. This experience can be categorized into four areas: enactive mastery, the experience of model learning, verbal persuasion, and physical arousal. Enacted mastery is considered the first source since it is derived from a teacher's experience in completing a task, both success and failure experiences. It means these experiences contribute insights for the teacher's understanding and competence in a certain task that will boost their confidence and foster their self-efficacy. Instead of self-experience, self-efficacy also derives from experiencing model learning, such as observing other people demonstrate to complete a certain task. In this way, the teacher learns from a role model, and this experience will affect the teacher's understanding of a task associated with concept and practice.

Moreover, self-efficacy emerges from support attained from the surroundings, such as colleagues' appraisals. The appraisal can result from evaluative feedback on the teacher's achievement provided by their colleagues. Furthermore, Physical arousal also creates self-efficacy such as emotional state: mood, stress, or subjective matters, and it will affect to teacher's performance in conducting a specific task.

Maintaining self-efficacy is essential for teachers in conducting the instructional design to achieve the learning outcomes. Van Gasse et al. [6] claim that selfefficacy leads to teachers' commitment, effort, and innovation in enacting the instruction, including in online learning instruction. Studies in motivation factors and integrated technology instruction show a connection between instructional practices and the motivator, in this case, the teacher. Motivation plays an important role in the success of any program, including in online instruction, since it impacts classroom quality improvement. Students' interaction and engagement is a crucial matter to achieve learning outcomes in online learning. As a result, a teacher needs to consider carefully the content used in the platform [3]. Moreover, Benson and Barck [7] suggest that course developers must consider not only the learning approach used but also the students' characteristics. It is seen that the teachers encountered complicated tasks; therefore, high motivation is needed to deal with the tasks, and it can be driven by self-efficacy.

\subsection{Designing e-learning and online learning}

The rapid growth of online learning, particularly in the Covid 19 pandemic, challenges teachers to provide online classes of the same high quality as traditional classes. However, students frequently encounter obstacles when using e-learning platforms since teachers are not always available when students may need help while learning. Besides, students also feel isolated for lack of the physical presence of classmates. Therefore, teachers must consider the design of e-learning that can support learning activities for students to have the best learning experience possible.

There are growing concerns about the shift from teaching in traditional classrooms to teaching online [9] since delivering courses online, and the learning activities provided for students are different. Teachers need to understand which features of e-learning platforms are effective for promoting learning. They also have to know how to apply these features in course delivery appropriately. Lister [10] lists some e-learning and online learning design trends, which can give us an overview for designing an appropriate online course. The trend includes structure, content presentation, collaboration and interaction, and feedback.

A good design of course structure is undeniably crucial in an online course. Ausburn's [11] review of the literature indicated that teachers or course designers must carefully consider the structure of online courses since it will benefit students. In fact, a clear course structure with clearly informed expectations, rubrics, and assignment examples was an essential part of an effective online course [12]. In addition, orientation at the start of the course can help students understand the features of the learning environment, which later can guide and direct them to achieve learning goals [9], [12].

Another thing that is also crucial in delivering an online course is the content presentation. Teachers and course designers also have to consider the content presentation of the online course since students can only interact with the screen. In addition, students valued the variety and choice of activities available in online learning. By providing students with choices in activities and topics, students can flexibly choose activities relevant to their needs and learning interests [11].

Many students and researchers comment that online learning courses lack interaction. Thus, teaching and learning strategies need to be improved to provide students with a convenient online learning environment and interaction with the teacher and other class members. Interaction among students and between students and teachers can be delivered synchronously through conferencing [13] and asynchronously through discussion forums, chat, and email [9]. In addition to that, West and Jones [14] noted that students asked for more possibilities for synchronized interaction since it can allow social engagement in a virtual classroom setting [13]. 
Feedback is a crucial part of the learning process, and this part needs to be considered when designing an online course. Gedik et al. [9] pointed out that students greatly valued fast and prompt feedback, but some teachers failed to meet this expectation. Therefore, teachers should take advantage of auto-correcting features in learning platforms which can help them provide students with more immediate feedback. Teachers also can incorporate self-assessments into the content presentation for timely feedback to students [12].

A good design course in E-learning will result in valuable benefits for students. Previous studies have indicated several benefits of e-learning, such as improving learners' performance and enhancing the adaptability of learning based on learners' pace and facilitating interactions [15]. For example, their studies investigating the effects of the online workbook on L2 vocabulary learning revealed that when learners were exposed to the online workbook and their conventional offline classes, their vocabulary improved significantly. At the same time, learners felt more comfortable studying because the flexibility of online learning allows them to learn at their own pace. According to Cheng and Tsai [16], this condition will promote selfefficacy for each learner in mastering their L2 and lead to learning progress [17].

Moreover, e-learning has facilitated interactions between teachers and learners and among learners, leading to better participation and satisfaction [18]. Even though e-learning facilitates interaction between teachers and learners, e-learning can also encourage learners to be more independent and requires less intrusion from their teachers [19]. Therefore, both teachers and learners can adjust their degree of interaction. All in all, owing to its primary strengths, namely flexibility, interactivity, and usefulness, elearning has become one of the superior approaches in today's teaching and learning.

\section{RESEARCH METHOD}

This study is conducted under a case study framework as this framework is appropriate to study a process and portray a certain phenomenon in particular setting. Moreover, it is compatible with the purpose of the study since it explores teachers' self-efficacy in digitizing course material in E-learning in a particular setting, in this case, vocational school, by investigating how the teachers perceive digital material and how they design and implement it in the E-learning.
Table 1. Question Prompts

\begin{tabular}{|l|l|}
\hline \multicolumn{1}{|c|}{$\begin{array}{c}\text { Sources of } \\
\text { Efficacy }\end{array}$} & \multicolumn{1}{|c|}{ Question Prompts } \\
\hline Article-Title & $\begin{array}{l}\text { Can you design digital material? } \\
\text { What problems do you encounter in } \\
\text { designing digital material? } \\
\text { How do you deal with those } \\
\text { problems? }\end{array}$ \\
\hline Author-Name & $\begin{array}{l}\text { What kind of training do you attend } \\
\text { before? }\end{array}$ \\
\hline Affiliation do you think about the \\
training?
\end{tabular}

\subsection{Participants}

This study involves 20 teachers at vocational schools who teach different subjects at different levels, and they are voluntarily involved in this study as participants. Most of them are experienced teachers with one up to sixteen years of teaching experience, and they use E-learning platforms to conduct online instruction specifically for about one year.

\subsection{Instrument}

Data in this study was garnered from a questionnaire and followed by interviewed and classroom observation. The questionnaire is developed under self-efficacy theory proposed by Bandura [8] with four sources of self-efficacy such as enactive mastery, the experience of model learning, verbal persuasion, and physical arousal.

\subsection{Data Analysis}

Collected data in this study, specifically questionnaire and interview, are coded based on critical incident appeared in the data. Then it was analyzed using the self-efficacy theory suggested by Bandura [8].

\subsubsection{Enactive mastery}

The teacher's experiences in designing digital material influence the way they perceive it. Most teachers state that E-learning is beneficial for conducting online instruction during pandemics; however, it requires the teachers' effort to transfer their course materials to digital formats. 
Table 2. The examples of Teaching Material in E-learning

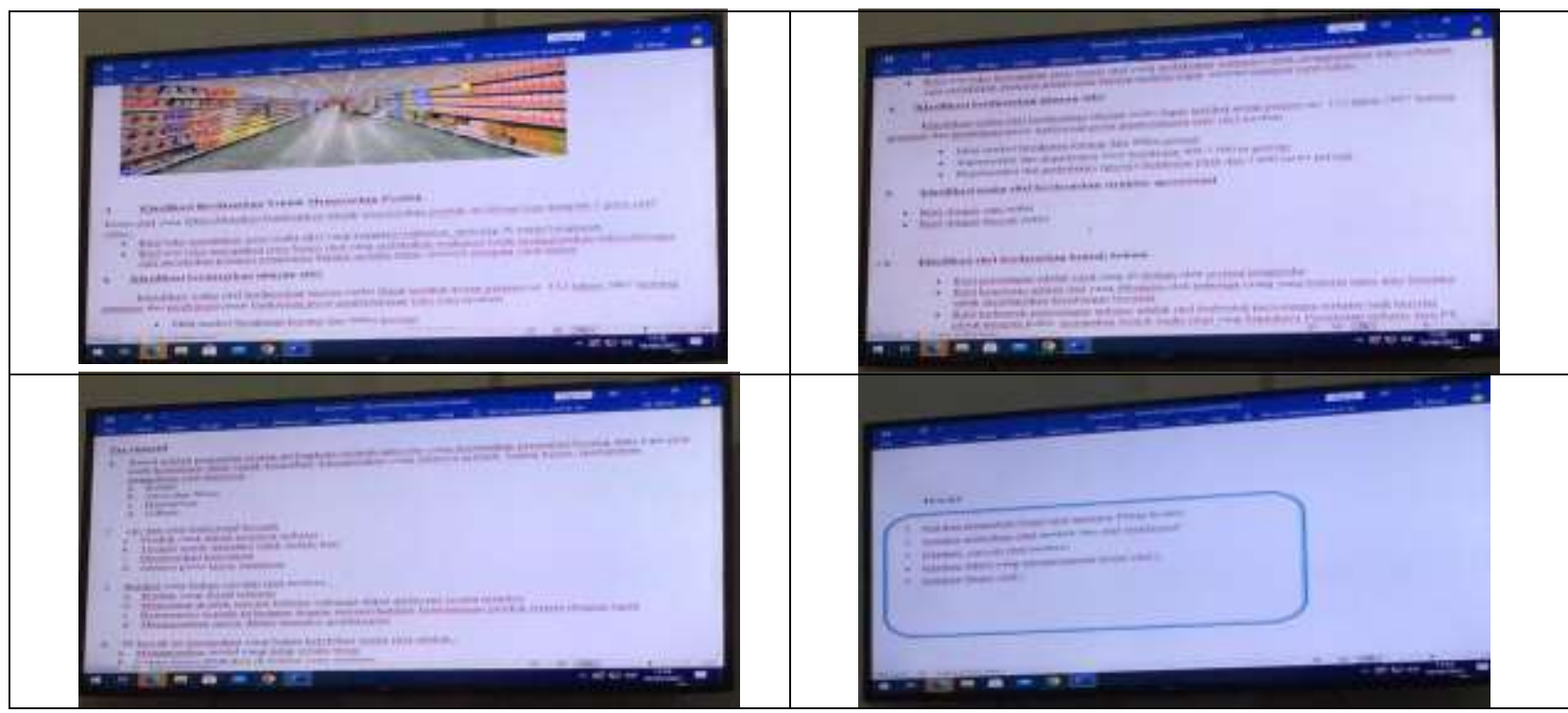

T9: "It is useful to conduct teaching and learning activities during the pandemic."

T1: "It is an online learning platform that assists teachers to deliver materials through its provided features."

T15: "It assists the teacher to conduct teaching instruction and administration."

T17: "Sometimes, trying new features is quite confusing. "

T19: "It takes time to try new features."

T19: "I must learn and practice to use it frequently."

T4: "Firstly, I write the module in MS word, then transform it into a PDF file and then upload it in E-learning."

T6: "I write the material in Words then put it into a drive; after that, insert the link to the $E$ learning.

T10: "I put the material collected from various sources in E-learning."

T5: "I still have a lot of weaknesses."

\subsubsection{Experience in model learning}

As transferring teaching mode from offline to online is a new experience for the teachers, they need to learn from a model. They gain this experience through attending the training conducted by the school and observing other teachings do the task.

T3: "My school listens to us, coaches, and provides us a tutorial video."

T2: "The school gave training to the teacher."

T7: "They provide more features in E-learning

T12: "They encourage teachers to ask other teachers or people who are more knowledgeable."

T14: "We upload the material together with other teachers so we can help each other"

\subsubsection{Verbal persuasion}

Another source of self-efficacy is verbal persuasion, or in other words, support and feedback received from colleagues for the efforts to complete a particular task.

T13: "I discuss with other teachers to search media which is more interactive."

T18: "I ask for help from my friends who are more knowledgeable."

T19: "The institution always responds quickly."

T20: "I consult with my colleagues to discuss my problem related to E-learning."

T15: "The school encourage us to learn and ask our friends if we face a problem."

\subsubsection{Physical arousal}

Physical arousal source means self-efficacy driven from emotion state when experiencing a certain task, including mood, stress, or subjective matter.

T11: "As long as we can catch up with the technology, it gives us an ease to conduct teaching instruction and to evaluate our students' learning progress."

T19: "I feel that it makes my teaching easy and effective."

T20: "It makes my job easier."

T16: "I learn a lot of new things, and those are meaningful for me, and they are easy to learn.”

\section{FINDINGS AND DISCUSSION}

\subsection{What is digital material and E-learning} perceived by teachers?

All the participants agree that digital material and E-learning are very useful for them since these provide ease for them to complete their instruction tasks such as delivering teaching material, evaluating their students' progress in learning, and managing administration. This condition aligns with Benson and Barck [7] claim that E-learning assists users in interacting with other users 
and the content and provides space for the users to manage the content. Moreover, the teachers believe that digitizing the material and using E-learning force them to learn more and more, starting from operating the Elearning features and preparing and designing their teaching materials to upload them in the E-learning. These experiences foster their self-efficacy, particularly for enactive mastery as Bandura [8] says, that someone experiences completing a certain task, both success and failure will lead to their self-efficacy.

Nevertheless, all the teachers encounter a problem during completing this task - transferring their teaching practice to an online platform as they said in the interview, they need more time to learn new applications and feel that they still have a lot of weaknesses dealing with E-learning. However, the valuable benefits of E-learning that they experience motivate them to keep learning to enhance their competency in using and maximizing the available features and applications in the platform. As a result, it can be concluded that their self-efficacy from enactive mastery is at a medium level since they have just started to use E-learning for about one or two semesters. This condition probably changes in a more positive direction since most of them state that they must keep learning to use E-learning in their teaching instruction. This situation corroborates Van Gasse et al.'s [6] statement that self-efficacy leads to teachers' commitment, effort, and innovation in enacting the instruction.

\subsection{How do the teachers design and implement digital material in E-learning?}

Initially, all the teachers gain knowledge and understanding regarding E-learning, including digitizing material from the workshops conducted by the institution or school. From this program, they learn how to operate E-learning for their class and design and implement it in their class in the E-learning. Indeed, they encounter problems during the process; however, they solve them by sharing and discussing the issue with other teachers who are more knowledgeable and observe other teachers completing the task. Therefore, they attain insight to improve their competence in digitizing the material and utilizing E-learning. It is seen that the teacher foster their self-efficacy through observing and collaborating with other people in completing the task, which is called modelling by Bandura [8]. Moreover, these activities also provide support and feedback for the teachers on what they have achieved. The institution will respond to the problems faced by the teachers immediately and create learning through a collaboration atmosphere; therefore, it creates self-efficacy from verbal arousal, and it can be concluded that the teachers' self-efficacy in this source is quite high.

It seems that all the teachers successfully transfer their teaching instruction to E-learning since they can conduct teaching and learning instruction through the platform. However, they realize that it is difficult to reach their students' participation and interaction during the online class. This problem emerges due to a lack of teachers' awareness of elements in designing online learning, as suggested by Lister [10], such as structure, content presentation, collaboration and interaction, and feedback. For instance, in content presentation, most teachers deliver their teaching material in word document format or text directly taken from the online source, and only a few use video. Therefore, it is very obvious seen that students merely read the material. As a result, students' interaction with the content is very limited, and this causes students' hesitation to join the class. Furthermore, according to Ausburn [11], students value variety and choice activities in online learning; therefore, the course developer must provide students with choices in activities and topics offered; consequently, they can flexibly select the relevant activities to their needs and learning interests.

Due to encountering this problem, teachers realize that designing and implementing online classes is a prerequisite. This situation motivates them to further enhance their competence as they realize that their knowledge and understanding are still superficial. This fact shows that teachers have positive emotions toward E-learning. Furthermore, it creates self-efficacy derived from physical arousal, forcing them to reach the ultimate teaching and learning instruction [8], [6].

\section{CONCLUSION}

It is undeniable that self-efficacy drives teachers to determine commitment, effort, and innovation in teaching and learning instruction through E-learning. Currently, the teachers' self-efficacy is at a medium level; however, it can be expanded to maximum level if they continuously receive comprehensive workshops on designing online courses by considering the crucial elements in online learning; therefore, it is urgent to provide teachers with comprehensive and continuous training on designing an online course.

\section{REFERENCES}

[1] J. Dobre. Learning Management System for higher education-an overview of available options for Higher Education Organizations. Procedia-Social Behavioral Science. vol. 180, pp.313-320, May, 2015 DOI: $10.1016 /$ j.sbspro.2015.02.122 [Accessed Jun.02, 2020]

[2] ] P.E. Ramirez-Correa, F.J. Rondan-Cataluna, J. Arenas-Gaitan, J.L. Alfaro-Perez. Moderating effect of learning styles on a learning management system's success. Telematics and Informatics. vol. 34, no.1, pp. 272-286, Feb, 2017. DOI: http://dx.doi.org/10.1016/j.tele.2016.04.006 [Accessed Jan. 12, 2020]

[3] I. Almarashdeh. Sharing instructors experience of learning management system: A technology perspective of user satisfaction in distance learning. Computers in Human Behaviour. Vol 63. pp. 249255. October 2016. DOI: http://dx.doi.org/10.1016/j.chb.2016.05.013 [Accessed Jan. 12, 2020] 
[4] UNESCO. Education: From disruption to recovery. Paris. 2021

https://en.unesco.org/covid19/educationresponse [Accessed Feb. 14, 2020]

[5] A.V. Joshi and M. Bhaskar. Impact of coronavirus on the Indian Education sector: perspectives of teachers on online teaching and assessments. Interactive Technology and Smart Education. 2020. ISSN: 1742-5659

[6] R. Van Gasse, K. Vanlommel, J. Vanhoof, P. Van Petegem. Teacher Instruction in taking action upon pupil learning outcome data: A matter of attitude and self-efficacy? Teaching and Teacher Education. vol. 89 March 2020. DOI: https://doi.org/10.1016/j.tate.2019.102989

[Accessed Mar. 15, 2020]

[7] R. Benson and C. Brack. Online Learning and Assessment in Higher Education: A planning guide. Chandos Publishing. Oxford. ISBN 9781 843345770

[8] A. Bandura. Self-Efficacy: The Exercise of Control. New York: Freeman, 1997

[9] N. Gedik, E. Kiraz, M.Y. Ozden. Designing of a blended learning environment: Considerations and implementation Issues. Australasian Journal of Educational Technology. vol. 1, no. 1, pp. 1-19, Feb. 2013 DOI:10.14742/ajet.6 [Accessed Jan. 20, 2020]

[10] M. Lister. Trends in the Design of E-Learning and Online Learning. MERLOT Journal of Online Learning and Teaching. vol. 10, no. 4, Dec 2014. https://jolt.merlot.org/vol10no4/Lister_1214.pdf [Accessed Jan. 20, 2020]

[11] L. J. Ausburn. Course design elements most valued by adult learners in blended online education environments: An American perspective. Educational Media International. vol. 41, no 1, pp. 327-337, Oct. $2011 . \quad$ DOI: https://doi.org/10.1080/0952398042000314820 [Accessed Jan. 15, 2021]

[12] M.K. Kim, S.M. Kim, O. Khera, J. Getman. The experience of three flipped classrooms in an urban university: An exploration of design principles. Internet and Higher Education. vol. 22, pp. 37-50, Jul. 2014. DOI:

https://doi.org/10.1016/j.iheduc.2014.04.003 [Accessed Feb. 20, 2021]

[13] J.L. McBrien, C. Rui, P. Jones. Virtual Spaces: Employing a Synchronous Online Classroom to Facilitate Student Engagement in Online Learning. International Review Of Research in Open and Distance Learning. vol. 10, no. 3, Jun. 2009 DOI:10.19173/irrodl.v10i3.605

[Accessed Apr. 26, 2021]

[14] E. west and P. Jones. A framework for planning technology used in teacher education programs that serve rural communities. Rural Special Education Quarterly. Vol 26 Issue 2. Pp. 3-15, Dec 2007. DOI: $10.1177 / 875687050702600402$

[Accessed May. 20, 2021]
[15] G. Zapata and N. Sagarra. CALL on hold: The delay benefits of an online workbook on L2 vocabulary learning. Computer Assisted Language Learning. vol 20, no. 2, pp. 153-17, May. 2007. DOI: https://doi.org/10.1080/09588220701331352 [Accessed Jun. 15, 2021]

[16] K. Cheng and C. Tsai. An investigation of Taiwan University students' perceptions of online academic help seeking, and their online learning self-efficacy. The Internet and Higher Education. vol. 14, no. 3, pp. 150-157, Apr. 2011.

DOI: https://doi.org/10.1016/j.iheduc.2011.04.002 [Accessed Sep. 15, 2020]

[17] J. Hong, M. Hwang, K. Tai, P. Lin. Instrinsic motivation of Chinese learning in predicting online learning self-efficacy and flow experience relevant to students' learning progress. Computer Assisted Language Learning. vol. 30, no. 6, pp. 552-574, May. 2017.

DOI:

https://doi.org/10.1080/09588221.2017.13292

[Accessed Aug. 15, 2020]

[18] H.T. Hung. Flipping the classroom for English language learners to foster active learning. Computer Assisted Language Learning. vol. 28. No.1, pp. 81-96, Oct. 2014.

DOI:

https://doi.org/10.1080/09588221.2014.967701

[Accessed Nov. 20, 2020]

[19] I. Mutambik. The role of E-learning in studying English as a foreign language in Saudi Arabia: Students' and teachers' perspectives. English Language Teaching. vol. 11, no. 5, pp. 74-83, Apr. 2018, DOI: http://dx.doi.org/10.5539/elt.v11n5p74

[Accessed Aug. 22, 2020] 